Article

\title{
Environmental Assessment Methodologies for Commercial Buildings: An Elicitation Study of U.S. Building Professionals' Beliefs on Leadership in Energy and Environmental Design (LEED)
}

\section{Jasmin Kientzel ${ }^{1, *}$ and Gerjo Kok ${ }^{2}$}

1 School of Governance and UNU-MERIT, Maastricht University, Keizer Karelplein 19, Maastricht 6211 TC, The Netherlands

2 Faculty of Psychology and Neuroscience, Department of Work and Social Psychology, Maastricht University, Universiteitssingel 40, Maastricht 6229 ER, The Netherlands;

E-Mail: g.kok@maastrichtuniversity.nl

* Author to whom correspondence should be addressed; E-Mail: jasmin.kientzel@maastrichtuniversity.nl; Tel.: +31-43-388-4485; Fax: 31-43-388-4499.

Received: 6 September 2011; in revised form: 14 November 2011 / Accepted: 15 November 2011 / Published: 12 December 2011

\begin{abstract}
Voluntary environmental programs (VEPs) have become increasingly popular around the world to address energy efficiency issues that mandatory building codes have not been able to tackle. Even though the utility of voluntary schemes is widely debated, they have become a de facto reality for many professionals in the building and construction sector. One topic that is neglected, however, in both academic and policy discussions, relates to how professionals (architects, engineers, real estate developers, etc.) perceive the rise of voluntary rating schemes. In order to fill this gap in the literature, the present study investigates beliefs underlying adoption behavior regarding one of the most prominent voluntary assessment and certification programs in the U.S. building industry, the Leadership in Energy and Environmental Design (LEED) scheme. In this paper, an elicitation study, based on 14 semi-structured interviews with building professionals in the North East of the United States, was conducted to analyze this question. Building on the Reasoned Action Approach, this paper shows that, in addition to more conventional factors such as financial calculations and marketing aspects, the understanding of beliefs held by
\end{abstract}


building professionals offers important insights into their decisions to work with Voluntary Environmental Assessment and Rating Programs.

Keywords: green buildings; LEED; voluntary environmental programs; environmental psychology; belief elicitation

\section{Introduction}

In both industrialized and developing countries, buildings have been found to be one of the major sources of greenhouse gas emissions and been linked to other environmentally damaging pollutants [1]. As a response to this pressing issue, energy efficiency and environmental assessment schemes, both mandatory and voluntary, have been implemented as policy instruments and strategies to reduce natural resource use and to improve energy efficiency within the building life cycle.

According to the United States Energy Information Administration (EIA) carbon emissions of the non-residential building sector in the United States grew about $25 \%$ faster than carbon emissions of the overall economy between 1971 and 2004 [1]. To counter these developments, international organizations, national governments, non-governmental organizations (NGOs) and other third party actors have established voluntary programs to improve environmental and energy issues in the building sector. On the supranational level, the European Union established the "Green Building Program" in 2005 while the United Nations followed the same year by creating their "Sustainable Buildings and Climate Initiative". Both schemes are voluntary in nature and build on a partnership approach with actors in the building industry. Voluntary approaches fall in line with what Fiorino [2] calls a "social learning approach" to environmental policy that includes different groups of stakeholders and actors.

In the commercial building sector, a large variety of voluntary assessment schemes have been developed to measure the environmental and energy impact of buildings. Some of the most prominent examples worldwide are the Leadership in Energy and Environmental Design (LEED), Green Globes and Building Research Establishment Environmental Assessment Method (BREEAM) schemes, launched by third party organizations. To this point, existing studies have mainly focused on the technical or financial aspects of these programs, while research on user perceptions has been scarce. However, in-depth analysis of behavioral factors can contribute significantly to a better understanding of sustainability practices in the building sector.

Some examples indicate that understanding architects, engineers and constructors' (AEC) beliefs and perceptions of sustainability programs is crucial. In 2009, a survey in the Architects' Magazine, a U.S. professional journal, revealed some astounding results: In this study, $71 \%$ of respondents stated that they know of someone, colleagues or other design professionals, "that do not believe that climate change is a major problem and/or do not believe that it is caused by human activity" [3]. While this survey has been developed outside of an academic framework and the accuracy of the results can be questioned to some extent, the results seem to indicate unpopularity of sustainable practices with building professionals. Indeed, sustainability practices depend largely on AEC professionals to be convinced that it is necessary and useful to apply them to their everyday work routines. 
Thus, this article does not seek to evaluate the effectiveness of the schemes or to evaluate whether the use of these schemes is normatively wrong or right but investigate the behavioral foundations of the LEED adoption in the United States. The main focus will be on the beliefs and perceptions of AEC professionals regarding working with VEPs. These beliefs and perceptions will ultimately influence decisions and behaviors but are embedded in a set of contextual factors briefly reviewed in the next section. The articles analysis section is based on the Reasoned Action Approach [4] as well as research on belief formation [5].

\section{Green Buildings in the United States: Between Building Codes and Voluntary Assessment Schemes}

Environmental assessment schemes for buildings are not a new phenomenon and numerous programs have appeared worldwide over the last twenty years [6,7] complementing existing building codes. During the 1990s, efforts to provide instructions on green buildings to building professionals have manifested in more institutional structures such as the creation of BREEAM in the UK, the Leadership in Energy and Environmental Design (LEED) Rating System in the United States and the Green Globes in Canada and the U.S. Despite this development, Fiorino [2] criticizes policy related to environmental issues frequently being grounded in purely technical principles. He suggests that behavioral and social learning approaches (such as VEPs) have been either neglected or badly executed.

Hence, much of the research on sustainable buildings has focused on technical aspects and economic benefits while research on human factors has been relatively scarce. The diffusion of Voluntary Rating and Assessment schemes has frequently been attributed to government and procurement efforts: Even though most VEPs have been developed by third party organizations, the importance of the government has been emphasized in previous studies. According to Smith et al. [8], demand for green buildings is driven largely by government building projects (municipal, state and federal). Government agencies as owners and buyers of commercial buildings also contribute to the increased use of third party certification schemes [1]. In order to understand the topic of voluntary green building assessment schemes in the United States, it is helpful to take a closer look at the building industry. As in most countries, the construction and building industry is mainly separated in two segments, residential and commercial housing (including offices, factories, public buildings, colleges, etc.). The building and construction industry in the U.S. is among the ten largest employment sectors and a large number of professional groups are involved in the process and work on building development, additions projects, and alterations of existing structures or maintenance [9]. As in most countries, the building construction process involves many stakeholders that differ from project to project and involve local officials issuing permits, investors, and commercial real estate developers, architects, building consultants, engineers as well as real estate brokers and corporate clients.

Some of the explanations of resistance to innovations in the U.S. building and construction industry (AEC) have been attributed to its horizontal (disciplines and professional groups) and vertical (in terms of project life cycle) fragmentation. However, issues of agency have been mentioned as preventing U.S. AEC professionals from adopting innovative approaches for sustainability [10]. These issues might be attributable to ad-hoc team composition which leads to barriers in the process of passing on tacit knowledge [11]. In the following sections, we wills briefly review the governance framework for 
buildings in the United States. For a more detailed review, including legislative acts issued by the U.S. federal government, Fischer [12] has provides an extensive overview.

\subsection{Energy Efficiency in the U.S. Building Sector: A Governance Issue and a Professional Challenge}

Since voluntary schemes have often been described as complementary measures beyond existing building codes, it is especially important to understand the interaction between both schemes. Building codes generally specify the level of health, safety and environmental concerns. In most countries, they are part of the legal framework in a certain jurisdiction on the international, national, regional or municipal level. It remains a special challenge that the building industry and the codes in the U.S. remain largely fragmented and building codes are established by a complex network of agencies [1]. Hart [1] suggests that fragmentation has been partly responsible for slow improvements in building energy performance.

While the U.S. Environmental Protection Agency has issued several programs and voluntary standards (e.g., Energy Star) on the federal level, individual state initiatives and local programs have also added to the governance complexity. In addition, voluntary certification schemes such as LEED are not the only initiatives related to green buildings: a number of Zero-Net Building initiatives, Building Life Cycle Assessments or the Passive house movement have added to the complexity of green building design and construction. Indeed, from a psychological point of view, the introduction of too many options can lead to the introduction of subjective uncertainty and influence beliefs, attitudes and behaviors.

\subsection{Literature on Green Buildings and LEED: Lack of Behavioral Studies}

The LEED (Leadership in Energy and Environmental Design) Green Building Rating System is a voluntary rating system introduced in 2000 for developing high performance sustainable buildings. Developed and maintained by the U.S. Green Building Council (USGBC), the certification process assigns points along six assessment areas (Sustainable Sites, Water Efficiency, Energy and Atmosphere, Materials and Resources, Indoor Environmental Air, Quality and Innovation). The USGBC is a non-profit and non-governmental organization whose members come from all sectors of the building industry. LEED aims to be a voluntary and transparent scheme in which the technical criteria developed under the supervision of specialized LEED committees are reviewed in a public process and by the USGBC. Based on the outcome, LEED Silver, Gold and Platinum certifications are awarded [13]. In addition to the building certification scheme, the LEED program also offers educational dimension, the LEED accredited professional (AP) qualification. Professionals from all over the building industry as well as public officials can take the USGBC administered test. While some professionals choose to become certified, this is not a pre-requisite for being able to work on a LEED building certification project.

There have been only a few studies focusing on behavioral factors underlying VEP adoption within the overall research on VEP and less so with special attention to the building industry. While schemes such as LEED have not been studied widely in a social science academic framework, the green building literature is much larger and diverse. Pitt et al. [14] provide a detailed discussion. Most of the studies on the LEED scheme have been published in professionals or trade journals focusing on 
articles on obtaining LEED credits and certifying [15-18], costs [19], choice of LEED credits [20], or rental prices [21]. Some authors have been very critical suggesting that the certification process might be too costly, too easy and encourages "point chasing" [22,23] or inconsistency with life-cycle analysis [24,25]. Most of the criticisms again focus mainly on technical or economic aspects while social or adoption processes are largely neglected.

Klotz [26], as one of the few articles on behavioral factors and green commercial buildings, suggested that buildings' energy performance is closely related to decisions made by architects, engineers and contractors during the planning and the construction phase of a project. Williams and Dair [27] suggested in their study on barriers to sustainable building that the most commonly found issues were sustainability measures not being considered by stakeholders. In addition, Hoffman and Henn [28] proposed that social and psychological barriers at individual, organizational and institutional levels are responsible for slow developments in the design and construction field. Nevertheless, none of these studies have investigated the underlying beliefs of AEC professionals that affect and contribute to the adoption of green building practices and in particular the LEED scheme.

\section{Conceptual Framework: Beliefs, Behavior and LEED}

Research on decisions on environmentally sensitive issues is plentiful, notably in the management and social psychology literature. Most of the management literature focuses on strategic [29,30], organizational or inter-organizational perspectives [31] while the current social psychology literature focuses on the determinants of pro-environmental behavior in household settings. To improve the understanding of the choices made by professionals, the present study aims to combine the two streams and analyze the behavioral foundations of LEED adoption by building professionals. An essential part of understanding decision-making and behavior is to focus on belief structures that guide intentions to engage in a specific form of action. Beliefs' elicitation has been a field of study that has gained more importance over the last twenty years with both economists and psychologists working on understanding the importance of beliefs on decision outcomes. For a broader overview on belief elicitation, see Grunert and Bech-Larsen [32], Rutstroem and Wilcox [33] and Ajzen et al. [34].

\subsection{The Reasoned Action Approach and Belief Elicitation}

This article aims to identify beliefs that underlie the eventual process of adopting the LEED scheme and to analyze beliefs influencing behavior at a later stage; we turned to models based on social cognitive theory. Social cognitive models suggest that an individuals' behavior is guided by cognitions about their direct environment. Part of personality psychology, there is a vast number of models including beliefs as predictors and behavior as outcome variables. Examples of these social cognition models applied to environmental issues are the Value-Belief-Norm Theory (VBN) [35] or the Reasoned Action Approach [4].

The framework to be used as a guideline for belief elicitation in this study is the Reasoned Action Approach [4], a social-psychological framework evaluating both internal and external factors that shape decisions and lead to a specific behavior. This model has frequently been used for studies on pro-environmental behavior and proven to be a very useful tool for this type of analysis. Even though its "pure form" has been applied mainly to decisions of individuals in a private decision context, such 
as household recycling behavior, it has also been used to study decisions in a professional context [36,37]. In addition, it is the basis of "applied models" in innovation research such as the Technology Acceptance Model [38,39].

The reasoned action approach builds on two predecessor models, the Theory of Reasoned Action [40] and the Theory of Planned Behavior [41] .The Theory of Reasoned Action [40] suggests that under volitional control, the behavior of the individual is determined by behavioral intention which is jointly determined by the attitude towards the specific behavior and subjective norms. These intentions to perform a behavior are generally good predictors of behavior [4]. Attitudes refer to an individual's perceptions of the inconveniences and advantages of performing a behavior while subjective norms are related to what an individual perceives to be important to other people around them.

Since not every behavior is under volitional control, Ajzen [41] included the construct of Perceived Behavioral Control (PBC) based on Bandura' s Self-Efficacy concept [42] and altered the name to "Theory of Planned Behavior" (TBP). PBC refers to 'the person's belief as to how easy or difficult performance of the behavior is likely to be' [41] and has an effect on behavioral intention and thereby on a specific behavior. In addition to the elements above, Fishbein and Ajzen added environmental factors, skills and abilities to the model to explain variance between intentions and subsequent behavior (see Figure 1) [4].

Figure 1. The reasoned action approach (Fishbein and Ajzen, 2010 [4]).

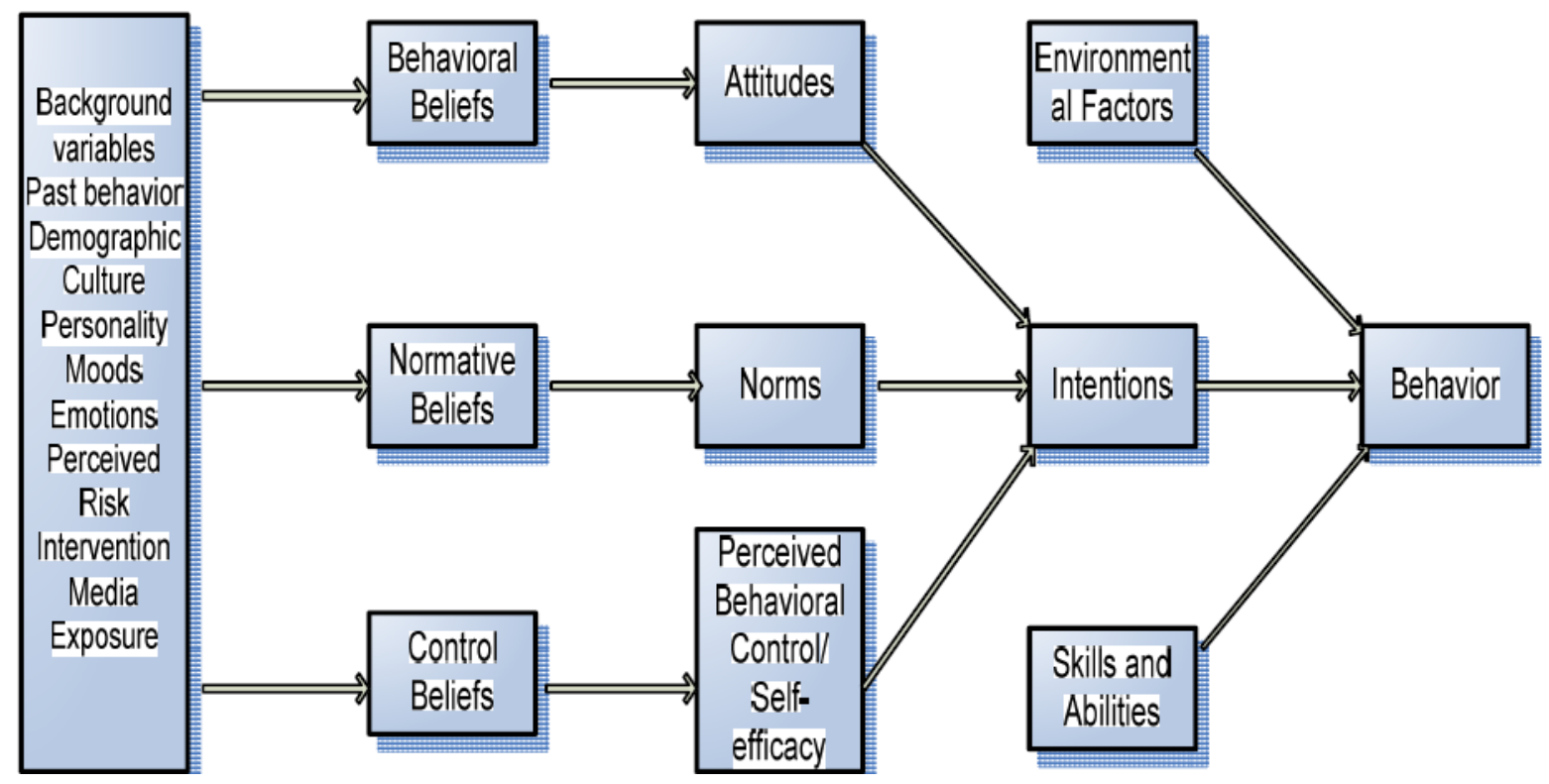

As for the context of this study, there are three separate interesting behaviors (1) Working with LEED guidelines and principles; (2) Working towards LEED certification; (3) Accreditation as a LEED AP. To distinguish these three sets of behaviors is important to take account of the TACT (Target, Action, Context, and Time) principle [4] to assure that the beliefs corresponding to a clearly identified behavior are measured. In this case, the "Target" is the building professionals; the "Action" is to work with the LEED scheme; the "Context" is sustainable building practices and assessment schemes while "Time" relates to current business practices. 
In this study, we focus mainly on the beliefs underlying the first two categories of behaviors, since they are closely related. As for the third category, LEED AP accreditation, we consider this as a potential preparatory behavior [43] intended to signal that a professional in question might be favorable to working with LEED. Salient beliefs underlying predictor variables determine attitudes, subjective norms and the perception of behavioral control. Figure 1 presents the theoretical framework applied to LEED adoption.

\subsection{The Importance of Beliefs in Decision-Making and Behavior Processes}

According to Fishbein and Ajzen [4], beliefs are "subjective probabilities". In the framework of the Reasoned Action Approach, behavioral beliefs "involve the subjective probability that performing a behavior leads to certain outcome". As for normative beliefs, injunctive normative beliefs are determined by subjective probabilities that specific stakeholders prescribe a certain behavior while descriptive normative beliefs involve the evaluation whether these stakeholders perform this behavior or not. Control beliefs include subjective probabilities about specific factors facilitating or barring performance of that specific behavior, in this case the LEED adoption process.

The three types of beliefs in the Reasoned Action Approach are determined by three main processes resulting in observational beliefs (by observing the behavior of others), informational beliefs (through outside information sources) and inferential beliefs (based on several inference processes). Normative, behavioral and control beliefs as well as their formation processes will form the basis of subsequent analysis. In the model, once beliefs are formed via these processes, they become the basis of attitudes, subjective norms and perceptions of control. Differences in beliefs, in turn, can be determined by a large variety of background factors such as demographic variables (including age, gender and ethnicity), personal dispositions (including variables such as self-esteem, intelligence, or sensation-seeking), knowledge, moods and emotions and the social environment [4]. Beyond the Reasoned Action Approach, other belief types such as beliefs based on past experiences [44] or shared beliefs [5] have also been found to influence intentions and behavior.

Fishbein and Ajzen [4] strongly recommend conducting an elicitation study to determine the underlying beliefs held by the target population(s). Elicitation studies establish the cognitive foundations of the beliefs the target population holds towards a specific behavior and tests the background influences and the beliefs underlying norms and attitudes towards and perceived control over a behavior [4]. In addition to the Reasoned Action Approach, which is open to the inclusion of new concepts and variables, elements from sociology of professions [45], social identity theory and inter-professional education [46] have found to be a useful addition to explain behavior in organizational and work place contexts. Since Fielding et al. [46] have incorporated these new approaches with the Reasoned Action Approach, we will consider elements from these frameworks where applicable.

Even though behavior can also determine beliefs in certain circumstances [47], and past behavior is included as a background variable we follow in this research project the assumption that belief structures from previous experiences are certainly a factor in certain cases [47] Additionally, it must be noted that if beliefs influence behavior at a later stage, then a two-step study is needed in which beliefs are elicited at a certain point in time and a behavior measured later [47]. Due to time constraints, costs 
and sampling issues, however, this is not always feasible and has been subject to major discussions in the relevant literature.

\section{Methods}

\subsection{Procedure}

The qualitative stage deals with obtaining information on beliefs regarding the LEED scheme. According to Ajzen [48], an elicitation study, usually in the form of interviews, is necessary to identify beliefs that are readily accessible in memory. The interviews in this study included open-ended questions and collected information regarding the respondents' reason for LEED certification and personal accreditation and sustainable building practices in general. Both the attitudes of professionals engaging in the LEED and scheme and those who do not were considered in the process.

The elicitation study was targeted at two professional groups in the building sector, architects and engineers. These professional groups have been chosen since they are the professions in which LEED is most widely used (See Figure 2, based on the USGBC membership directory [13]).

Figure 2. Professional groups represented in the USGBC based on [13].

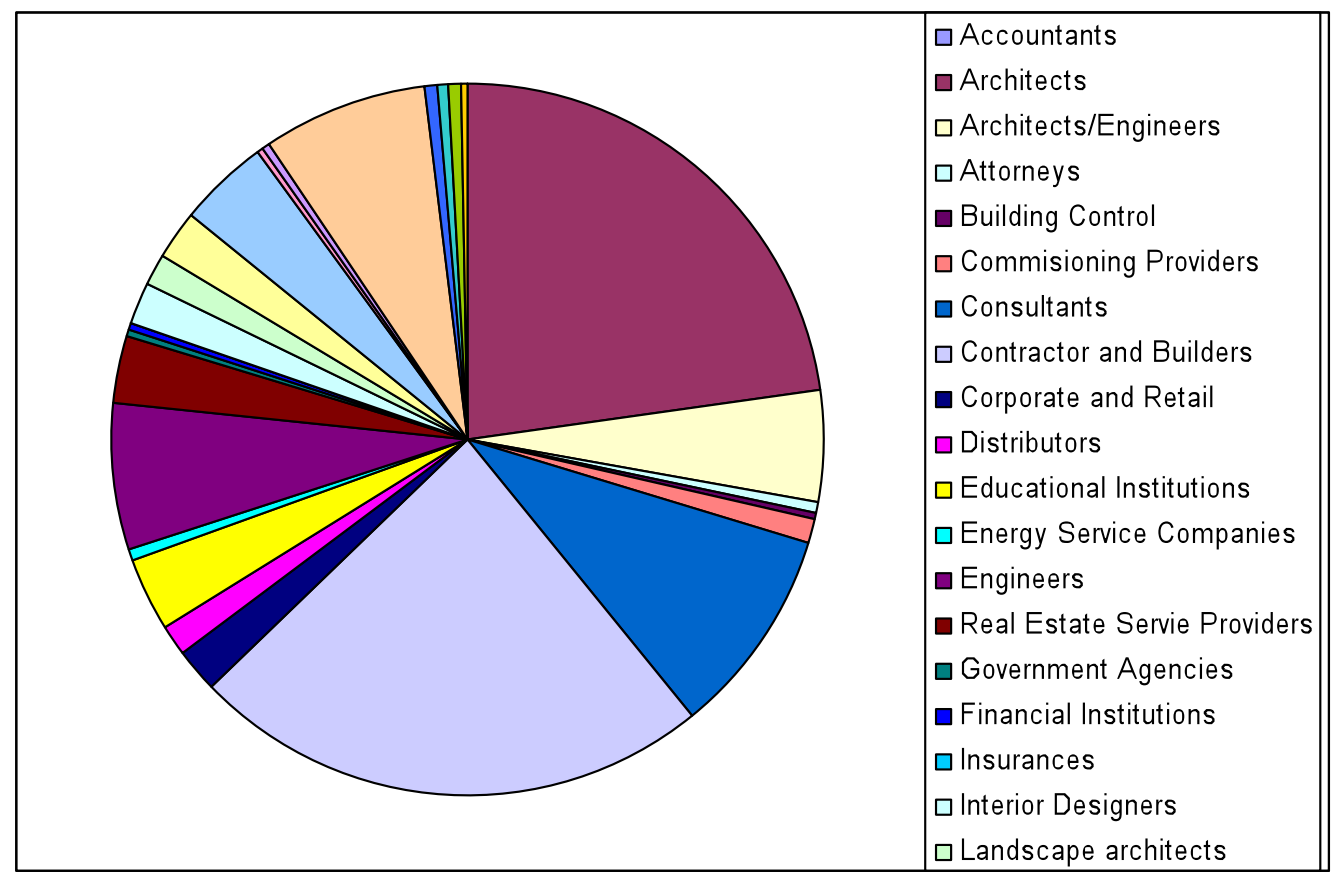

\subsection{Sample}

The elicitation study was conducted in April and May 2010 in the North East of the United States, with architects and engineers as interviewees. The participants were identified and selected via the U.S. Green Building Council Member database and professional accreditation organizations to avoid bias towards building professionals holding positive perceptions and beliefs towards LEED. From this database consisting of 300 entries, 40 building professionals were randomly chosen.

They were first contacted by email in order to make an appointment for a subsequent face-to-face interview. From the selected sample of 40 building professionals, 14 agreed to an extensive face-to-face 
expert interview. As a consequence, the study consisted of a convenience sample. Fourteen interviews were conducted that lasted between 30 to 60 minutes. In total, ten architects ( 8 male and 2 female) and four engineers ( 4 male) participated in the study. Three of the interviewees were not LEED accredited while the other eleven had taken the LEED AP test and were involved in LEED projects in the past. The average age was 52.3 years and 12 interviewees held senior positions (CEO or partner) in their companies.

\subsection{Data Analysis}

The analysis conducted followed the recommendations given by Ajzen and Fishbein [4] to perform a content analysis to determine the salient beliefs of the interviewees regarding sustainability practices and LEED adoption. Using NVivo software for qualitative analysis, the participants' responses to the semi- structured interview questions were selected and grouped electronically following the method suggested by Fonteyn and Bauer-Wu [49]. The questions were loosely based on the proposed theoretical framework but allowed for emerging themes.

All the interviews were audio-taped, transcribed manually and then imported into NVivo. The analysis started with a review of the transcripts in which the themes and key concepts were identified [49]. The use of NVivo [50] facilitated the identification of emergent themes across individuals' responses and the thematic content analysis of the interview transcripts. We adopted the method suggested by Vinnicombe and Singh [51] and developed a coding structure by using key concepts emerging from the data. The next step was then to code text at the nodes of interest after which the participants' responses were examined in sets in order to identify emerging patterns from the data. These nodes were then positioned as seen fit in the analytical framework. Sets of responses were categorized to a number of nodes and particular themes; proceeding this way and categorizing data to the different nodes allows for "an overall confidence in the coding and a clear audit trail through the findings" [52].

The analysis focused on the three types of beliefs (normative, behavioral and control) and explored which type of belief formation might have been the basis for these beliefs.

\section{Results of the Elicitation Study}

During the transcript analysis, beliefs were categorized building on the proposed framework as well as additional topics that came up repeatedly during the interview process. Beliefs were regrouped building on the underlying framework, the Reasoned Action Approach [4]. Based on the Reasoned Action Approach, behavioral, normative and control beliefs are crucial to understanding of the impact that attitudes, norms and self-efficacy have on the intentions of building professionals to adopt the LEED scheme.

\subsection{Normative Beliefs: Government and Client Demands}

As stipulated by the Reasoned Action Approach [4], normative beliefs shape perceptions of norms and eventually influence intentions to engage in specific behaviors. The main theme in the normative beliefs section is to identify the stakeholders believed to have a large impact on building professionals' 
decision to work with the scheme. Both descriptive and injunctive normative beliefs were mentioned by the respondents. In addition, two main groups of stakeholders were believed by interviewees to have a large influence on their LEED adoption process: governmental authorities and clients.

\subsubsection{Government Expectations}

The role of government expectations, either as a client or legislator, was stressed by the interviewees. Whether governments actually expect building professionals to engage in LEED is another story; however, respondents believe that governmental authorities do want them to apply voluntary environmental assessment schemes in their projects.

"The U.S. government is actually one of the first adopters of LEED” (Respondent 3, architect)

This is particularly insightful, since LEED is a third party sponsored scheme and some state governments and city councils have similar parallel programs. These findings are in line with Smith et al. [8] and Hart [1] suggesting the importance of government support for VEPs in the building sector and also confirm the predictions of the Reasoned Action Approach postulating that perceived social norms influence human intentions, decisions and behavior. Government expectations, however, were not only seen as a burden but also as helpful resources for the implementation of the LEED scheme:

"Government support is absolutely critical; many would not do it if there was no one helping them with it" (Respondent 7, architect)

Government support and action in this area included hence both injunctive ("government support is critical") as well as descriptive normative beliefs ("the government acted first"). Both normative beliefs seem to play a role in the personal evaluation of building professionals evaluation of the LEED scheme. In the present sample, these beliefs were formed by observation, information and inference, so all three forms of belief formation were present, as stipulated by the Reasoned Action Approach [4].

\subsubsection{Client Demands}

Governments were mentioned frequently, but even more predominant was the perception of clients' expectations and demands. Clients' (defined in a larger sense, not only the building owners) expectations were believed to influence the adoption of the LEED scheme significantly.

\section{"It is required by clients" (Respondent 6, architect)}

These results are hardly surprising given that the adoption of VEPs generally takes place in a business transaction environment. Therefore, these findings are in line with the mainstream business and management literature. However, the interviewees display different perceptions of clients' roles.

"It is coming from owners. They are more pushing for the principles because they know LEED certification" (Respondent 7, architect). 
The interviewees emphasized the difficulty of adopting LEED when owners were not on board initially, but did not deem it impossible to convince them. In this aspect, many interviewees did not see themselves as merely passive actors but also as potential decision-makers influencing social norms in the building sector.

"We find that LEED is difficult with the type of clients we have, mostly commercial clients. It is a difficult thing for owners to swallow" (Respondent 7, architect).

Hence, some interviewees did see a potential for influencing and manipulating others behaviors and perceived social norms (i.e., convincing building owners in order to be able to adopt the LEED standard).This aspect is linked to the concept of control beliefs in the Reasoned Action Model, which we will come back to in more detail.

Both injunctive ("It was required by a client") and descriptive normative beliefs ("Owners know and use the LEED scheme") were found in this category. Observational, informational and inferential beliefs were the result of several belief formation processes, in line with theory [4].

Aside from government and clients, other professional groups were also mentioned as factors to adopt the LEED scheme. Other professional groups, however, were more frequently mentioned as motivating factors. For this reason, this aspect will be discussed in the following section.

\subsection{Behavioral Beliefs: Sustainability Education and Communication}

In this segment, the findings were less intuitive than in the normative beliefs section. Behavioral beliefs, which relate to the motivations of AEC professionals to work with the LEED scheme, centered on educational aspects, sustainability practices in their profession and communication between professional groups.

\subsubsection{Education and Sustainability Practices}

A recurring theme was the educational aspect of LEED as an important factor for decisions to adopt the scheme. Two main emerging themes were the roles of the LEED accreditation exam and the role LEED assumes in educating building professionals about sustainability.

"So LEED has helped to raise awareness and has helped to educate people but it is a very simplistic tool for a very complicated issue" (Respondent 5, architect)

The role of educational components within VEP programs has been neglected by the academic literature to a large extent. Even though education is one of the major strategies in intervention studies aimed at encouraging pro-environmental behavior at the household level, the issue of educational aspects has not been discussed so far within VEP adoption literature. Frequently, education levels have been considered as a determinant of VEP adoption, while the effect of including educational components within a program has not been subject to much attention [53].

"I think that it is very helpful to have gone through the educational portion, even though it is directed at a very specific scheme. The LEED scheme did introduce new concepts to me, but also made me 
realize that the LEED scheme is in some points not as sophisticated as I expected it to be" (Respondent 7, architect)

However, as can be seen from the interviewees' statements, the LEED scheme is also a helpful tool to gain more knowledge on environmental issues but they emphasized at the same time the limitations of the scheme:

"The whole point of the LEED program was to change the way things were being done. So, there is a certain amount of reeducation but not complete reeducation" (Respondent 12, architect)

In this section, most beliefs were of inferential nature, observational and informational beliefs were of lesser importance.

\subsubsection{Communication Aspects}

Additionally, LEED was identified by the interviewees as a useful communication tool that has altered the way different groups of building professionals interact.

"It has provided a common language" (Respondent 5, architect)

In this respect LEED is regarded by the respondents as a tool for bridging this gap in practices and hence constituting a "common language". These findings are related to the literatures on sociology of professions [45], social identity theories and inter-professional education [46] found to be a useful addition to the Reasoned Action Approach and its conceptual predecessors in this context.

"With LEED it is probably easier in terms of a common principle and language when it comes to buildings. Now there are more voices to orchestrate; this can be a challenge" (Respondent 8, architect)

While some professionals mentioned the unifying function of the LEED principle, others suggested that there were not so many differences between professions and their adoption and use of sustainable building practices.

"I do not sense a difference in how it is used and interpreted by disciplines. Where you see some differences is the-and maybe that is too far off-topic-but one of the good thing about LEED is that it is written by a consensus process where there are stakeholders all aspects of the building industry"(Respondent 3, engineer)

Hence, some interviewees believed that the LEED scheme is establishes a consensual decision process and thereby fosters their acceptance of the scheme. The beliefs stated in this aspect were of mainly inferential nature.

\subsection{Control Beliefs: Organizational Culture and Capabilities, Financial Constraints and Inter-Professional Relations}

Control beliefs in the sense of the Reasoned Action Approach refer to the interviewees' perceived ease to work with the LEED scheme or to obtain LEED accreditation. Several barriers were mentioned 
preventing the respondents from engaging in the LEED program. In some cases, the company was said to have made the decision to work with LEED and tell their employees to get accredited. In other cases, the decision was up to the employees themselves. Other respondents indicated willingness but faced resistance in their direct professional environment.

\subsubsection{Organizational Culture}

Organizational culture was regarded as a major factor in the choice to include a voluntary building scheme in their work practices. Some interviewees considered the choice to work with the LEED scheme or to become accredited to be a fully personal one over which they had complete volitional control. Voluntarism is one of the major dimensions of "Voluntary Environmental Programs" and their adoptions can be seen as "voluntary" on the firm level. While in traditional companies managers and executives usually decide whether a firm engages in a scheme that in consequence applies to the whole organization, the situation is not so clean cut in the AEC industry in which certification processes usually occur on a project basis. For most of the respondents, the voluntary aspect is a major advantage of the scheme:

"It is perfectly voluntary, you do not need it to work on LEED projects, it is something I think that, you know, demonstrates a personal commitment because it is voluntary..." (Respondent 11, architect)

On the other side of the spectrum, participants felt that the choice to work with LEED did not depend on their own will, choice or attitudes, and hence perceived low volitional control over the process.

"Oh, it [the decision] was made for me. The president of my company tells me to do it [work with the LEED scheme]" (Respondent 12, engineer)

"I have been through a battle just to introduce LEED into our regime in the office" (Respondent 7 , architect)

Hence, there are two very different levels of volitional control that have to be considered which depend very much on the situation an individual occupies in an organization. While the decision within a firm is frequently not perceived to be under volitional control, company owners might perceive to have a higher volitional control over the choice to adopt a VEP. This, however, needs to be verified since they might also feel constraints to adopting voluntary environmental assessment and rating schemes that have not been mentioned in the present study.

Beliefs related to organizational culture focused were mainly of informational nature with the feedback given by co-workers and managers as a major influence.

\subsubsection{Financial Constraints}

Other perceived barriers over the LEED adoption were related to financial constraints during the construction project.

"We designed a building the LEED way and when the price came, it could not be afforded" (Respondent 5, architect) 
Since the fulfillment of LEED credits and subsequent documentation may increases a building project's cost, this factor is rather intuitive and supported by the mainstream economic and management literature. The beliefs were mainly of observational ("other firms had this issue") and inferential nature ("since costs have been an issue for other firms, we are likely to have an issue too").

\subsubsection{Organizational Capacities}

Available capacities in the respondents' organizations were mentioned as influencing the control interviewees believe to exert over the adoption process.

"We had a client who wanted us to look at things that are related to LEED and we did not have the capacity to do them" (Respondent 11, architect)

Even though most of the interviewees cited past experiences as a major factor, inference and observation were also cited as a major factor in this respect. Even though some firms might have the capacity to adopt the LEED scheme, there seems to be a prevalent belief that "special skills" are needed to cope with the additional work that a scheme such as LEED might entail. Beliefs on organizational capacities were mainly based on past experiences and of observational and informational nature.

\subsubsection{Inter-Professional Relations}

To some respondents another barrier was related to the topic of inter-professional cooperation. This is a crucial point, since building projects involve a large number of different professional groups that have to work together in order to make the construction process successful.

"You have to have everyone on board with the same mindset. This is why it is hard to get a sweeping effort together" (Respondent 11, architect)

As mentioned in the results on sustainability practices and communication, inter-professional relations and cooperation can not only be a facilitation factor for adopting a VEP but can also represent a barrier, depending on the personal beliefs of the respondent. Most of the beliefs in this section were of inferential nature and related to past experiences.

Overall, when applying the findings of this research study to the framework developed by Fishbein and Ajzen [4], the following attitudes, norms and control perceptions were detected (Figure 3).

When combining the belief type with the belief process for each category, the following patterns were detected in the data.

As Table 1 suggests, normative beliefs on government and client influences were formed by informational, observational and inferential processes. In contrast, behavioral beliefs on sustainability practices and communication were found to be of mainly inferential nature. Control beliefs were the most complex category since beliefs on inter-professional relations were mainly inferential while financial constraints were found to be mainly observational. Beliefs on limiting organizational capabilities were found to be observational and informational mainly while control beliefs on organizational culture were primarily informational. This analysis provides interesting insights not 
only on the nature of the beliefs but also the belief formation processes in relation to LEED adoption processes. Hence, the data generated touches not only upon the beliefs interviewees held in this respect but also on the way these beliefs were formed.

Figure 3. Behavioral, normative and control beliefs applied to Leadership in Energy and Environmental Design (LEED) adoption (Adapted from Fishbein and Ajzen, 2010 [4]).

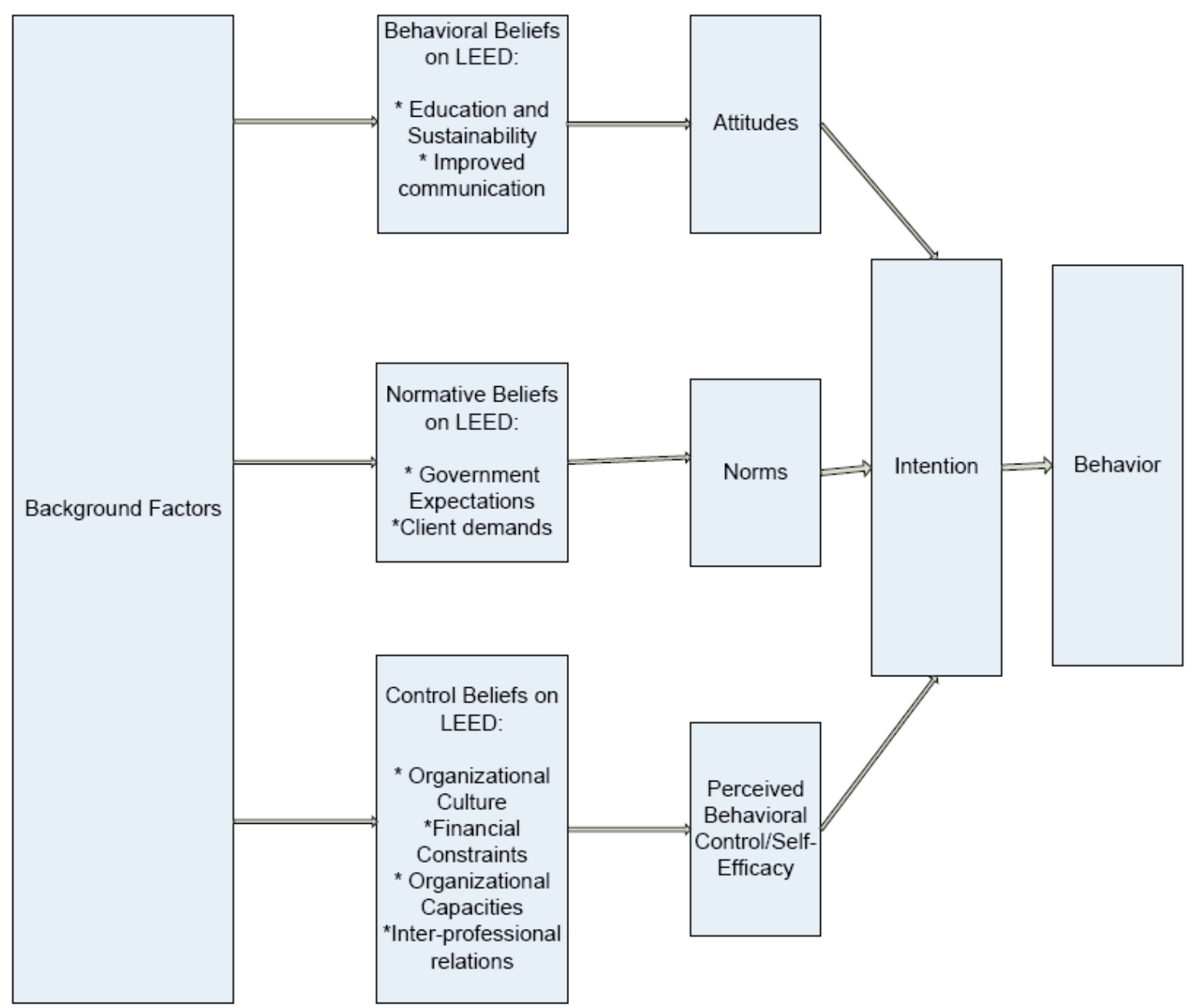

Table 1. Belief and belief formation adapted from the Reasoned Action Approach (Fishbein and Ajzen, 2010 [4]).

\begin{tabular}{|c|c|c|c|}
\hline Belief type/ Process formation & Inferential & Observational & Informational \\
\hline Normative & Government Clients & Government Clients & Government Clients \\
\hline Behavioral & $\begin{array}{l}\text { Education and } \\
\text { Sustainability } \\
\text { Communication }\end{array}$ & & \\
\hline Control & $\begin{array}{l}\text { Inter-professional } \\
\text { Relations }\end{array}$ & $\begin{array}{l}\text { Financial constraints } \\
\text { Organizational } \\
\text { capacities }\end{array}$ & $\begin{array}{l}\text { Organizational Culture } \\
\text { Organizational } \\
\text { capacities }\end{array}$ \\
\hline
\end{tabular}


Observational beliefs have been found to be the most influential [40] for subsequent beliefs and behaviors. Inferential beliefs are usually based on prior observational beliefs via past experiences while information received facilitates the formation of new or the transformation of existing beliefs. Thus, according to theory, government and client influences, financial constraints and organizational capabilities should be most influential aside sustainability education, communication aspects and beliefs on the improvement of inter-professional relations due to LEED adoption processes.

\section{Discussion}

The present study based on the Reasoned Action Approach shows that not only financial and marketing concerns or career motives, as often postulated in the management literature, influence adoption behavior of VEPs. The assumption that beliefs play a major role in VEP adoption processes has been confirmed in this study. The data analysis shows some interesting results which emphasize the limitations of current research programs in the area of VEP research. A stronger focus on behavioral factors including motivations, beliefs, norms, values and self-efficacy is necessary to understand adoption decisions in a more comprehensive way. This study demonstrates how essential qualitative elements are in the exploratory phase of a new research program, even if only used for quantitatively-oriented studies

In the case of LEED, in line with the Reasoned Action Approach, normative, behavioral and control beliefs seem to play a significant role in understanding VEP adoption practices.

As for the normative beliefs, the insights gained are very much in line with the existing management and psychology literature, i.e., that government and client demands play a significant role when it comes to LEED uptake. However, the results also point towards AEC professionals not being merely perceiving the influence of social norms but also influencing the decisions of other building professionals in adoption decision processes. This factor links to the control belief section.

Analyzing control beliefs, several factors constituted barriers to working with the LEED scheme. First, some of the respondents felt that they were very much in control of the process while others believed that the decision was made for them either explicitly or implicitly. Barriers to LEED uptake were closely linked to prohibitive organizational structures, financial constraints, and a lack of organizational capacities. In addition, inter-professional relations were also perceived to constitute a barrier to standards adoption if not all building professions work on a project in the same mindset.

Behavioral beliefs are for some participants very much influenced by advantages linked to improved sustainability practices, the provision of an educational platform for sustainability practices and communication between building professionals. This may seem surprising given that "egoistic" motives such as career advancement or merely business benefits do not constitute the prime concern for most of the interviewees.

The beliefs with regards to LEED adoption were, in line with the Reasoned Action Approach, found to be formed by observational, informational and inferential processes. Behavioral beliefs were found to have been formed via inferential processes, while normative and control beliefs were formed by inferential, control and observational processes. The mainstream assumption that concerns of government support, client demands, financial constraints and organizational capabilities were of major importance was confirmed. These results, however, were supplemented by other less intuitive 
beliefs such as educational, communication and interaction with other professional groups in the construction industry. These results are new in the context of LEED adoption and should be explored in more detail in the future.

\section{Limitations of the Study}

Since the present article describes an elicitation study required within the Reasoned Action Approach, we did not test the theory in a conventional sense. In this study, we focused on eliciting beliefs and belief formation underlying LEED adoption in the U.S. building industry. Beliefs have been recognized as a major factor underlying behavioral and decision analysis. Hence, the study of beliefs in the building industry is neglected but important for policies and behavior change programs. Research on beliefs and belief formation has come a long way but is still not systematically investigated in policy-oriented and academic research studies. This article suggests that belief elicitation is a useful and often necessary tool to understand professional judgment and behavior.

However, it must be noted that the findings presented in this section are limited to the fourteen respondents interviewed and their perceptions and beliefs of the LEED scheme and green building practices. Therefore, the present study can only be the first step in understanding beliefs and behavior related to LEED adoption. Despite the low sample size, the in-depth interviews reveal important insights in belief structures underlying VEP adoption processes, an important topic neglected so far.

While at this stage, the data cannot be regarded to be applicable to a wider range of building professionals, this article suggests that more research on beliefs and belief formation needs to complement "mainstream" assumptions in management and construction research.

A particular issue when conducting a study with professional groups is to determine in which ways salient beliefs are part of their individual domain or imposed by their adherence to a given professional group. It is understood, that for better validity other professional groups in the building industry aside architects and engineers must be included in future studies in order to gain a better understanding of the overall beliefs held by professionals in this industry and their adoption behavior.

\section{Conclusions}

Using the Reasoned Action Approach to identify beliefs and belief formation processes underlying LEED adoption practices yielded in depth results. The elicitation study analyzed behavioral, normative or control beliefs of engineers and architects that might influence their decision to work with the scheme and obtain professional accreditation. The results revealed that the uptake of the LEED scheme is related to the importance of government support, the role of client demands, individual attitudes, group efforts, barriers, educational aspects, and communication aspects, as well as the position of LEED in the overall green building governance structure.

By examining the underlying beliefs of building professionals, a first step has been made to better understand the reasons for adopting a Voluntary Environmental Program. Behavioral factors leading professionals to engage in VEPs clearly warrant further investigation using quantitative techniques to achieve more generalizable results. This approach would also allow for distinguishing beliefs between LEED participants and non-participating individuals as well as between adopters of LEED and other comparable schemes. 
This information is valuable for planning future studies evaluating adoption motivations, intentions and subsequent behavior of building professionals regarding Voluntary Environmental Programs. In addition, the knowledge gained has also the potential to improve the design of future VEPs. Without identifying the behavioral foundations, including underlying beliefs of these schemes, programs are more likely to face resistance, to fail or to be misused within the policy mix for sustainability.

\section{References and Notes}

1. Hart, D.M. Don't Worry about the Government? The LEED-NC “Green Building Rating System and Energy Efficiency in U.S. Commercial Buildings; MIT-IPC-Energy Innovation Working Paper Cambridge; Massachusetts Institute of Technology: Cambridge, MA, USA, 2009.

2. Fiorino, D.J. Environmental policy as learning: A new view of an old landscape. Public Adm. Rev. 2001, 61, 322-334.

3. Hurley, A.K. The wide spectrum of green. Archit. Mag., in press.

4. Fishbein, M.; Ajzen, I. Predicting and Changing Behavior: The Reasoned Action Approach; Psychology Press: London, UK, 2010.

5. Bar-Tal, D. Shared Beliefs in a Society; Sage: Thousand Oaks, CA, USA, 2000.

6. Todd, J.A.; Crawley, D.; Geissler, S.; Lindsey, G. Comparative assessment of environmental performance tools and the role of the Green Building Challenge. Build. Res. Inf. 2001, 29, 324-335.

7. Liu, Y.; Prasad, D.; Li, J.; Fu, Y.; Liu, J. A holistic approach to developing regionally specific framework for green building assessment tools in China. In Proceedings of the 2005 World Sustainable Building Conference, Tokyo, Japan, 27-29 September 2005.

8. Smith, T.; Fischlein, M.; Suh, S.; Huelman, P. Green Building Rating Systems: A Comparison of the LEED and Green Globes Systems in the U.S.; University of Minnesota Press: Minneapolis, MN, USA, 2006.

9. Doleta (United States Department of Labor). America's Construction Industry: Identifying and Addressing Workforce Challenges; Department of Labor: Washington, DC, USA, 2004.

10. Sheffer, D.; Levitt, R.E. The diffusion of energy saving technologies in the building industry: Structural barriers and possible solutions. In Collaboratory for Research on Global Projects; Stanford University: Stanford, CA, USA, 2010.

11. Augier, M.; Vendelo, M.T. Networks, cognition and management of tacit knowledge. J. Knowl. Manag. 1999, 3, 252-261.

12. Fischer, E.A. Issues in green building and the federal response: An introduction. In CRS Report for Congress; Congressional Research Service: Washington, DC, USA, 2010.

13. Green Building Council, USGBC Member Directory, 2011. U.S. Green Building Council Web site. Available online: http:/www.usgbc.org/myUSGBC/Members/MembersDirectory.aspx?PageID= 2011\&CMSPageID=140 (accessed on 22 November 2011).

14. Pitt, M.; Tucker, M.; Riley, M.; Longden, J. Towards sustainable construction: Promotion and best practices. Constr. Innov. 2009, 9, 201-224.

15. Vangeem, M.G.; Marceau, M.L. Using concrete to maximize LEED TM points. Concr. Int. 2002, 24, 69-74.

16. Herrmann, R.K. Building automation and LEED credits. ASHRAE J. 2005, 47, 10-17. 
17. Yoon, Y.J.; Moeck, M. Two Studies that investigate the impact of ceiling and wall reflectance values on LEED credits. J. Archit. Eng. 2005, 11, 81-90.

18. Davis, E.D. Water conservation strategies for LEED points. Landsc. Archit. 2005, 95, 64-71.

19. Kats, G.; Capital, E. The Costs and Financial Benefits of Green Buildings: A Report to California's Sustainable Building Task Force; California Sustainable Building Task Force: Sacramento, CA, USA, 2003.

20. Eichholtz, P.; Kok, N.; Quigley, J.M. Doing well by doing good? Green office buildings. In Center for the Study of Energy Markets Working Paper Series; University of California Energy Institute: Berkeley, CA, USA, 2009.

21. Rumsey, P.; McLellan, J.F. The Green Edge-The Green Imperative. Environ. Des. Constr., 7 March 2005, 55-56.

22. Schendler, A.; Udall, R. LEED is broken, let's fix it. Grist Mag., October 26. Available online: http://www.grist.org/article/leed (Accessed 22 November 2011).

23. Bowyer, J.; Howe, J.; Fernholz, K.; Lindburg, A. Designation of Environmentally Preferable Building Materials-Fundamental Change Needed within LEED; Dovetail Partners. Inc.: White Bear Lake, MN, USA, 2006.

24. Scheuer, C.W.; Keoleian, G.A. Evaluation of LEEDTM Using Life Cycle Assessment Methods; National Institute of Standards and Technology: Gaithersburg, MD, USA, 2002.

25. Klotz, L. Cognitive biases in energy decisions during the planning, design, and construction of commercial buildings in the United States: An analytical framework and research needs. Energy Effic. 2010, 1-14.

26. Williams, K.; Dair, C. What is stopping sustainable building in England? Barriers experienced by stakeholders in delivering sustainable developments. Sustain. Dev. 2007, 15, 135-147.

27. Hoffman, A.J.; Henn, R. Overcoming the social and psychological barriers to green building. Org. Environ. 2008, 21, 390-419.

28. Aragon-Correa, J.A. Strategic pro-activity and firm approach to the natural environment. Acad. Manag. 1998, 41, 556-567.

29. Stead, W.E.; Stead, J.G. An empirical investigation of sustainability strategy implementation in industrial organizations. In Research in Corporate Social Performance and Policy; JAI Press: Greenwich, CT, USA, 1995.

30. Lawrence, A.T.; Morell, D. Leading-edge environmental management: Motivation, opportunity, resources, and processes. In Research in Corporate Social Performance and Policy; JAI Press: Inc.: Stamford, CT, USA, 1995.

31. Clair, J.A.; Milliman, J.; Mitroff, I. Clash or cooperation? Understanding environmental organizations and their relationship to business. Res. Corp. Soc. Perform. Policy 1995, S1, 163-193.

32. Grunert, K.G.; Bech-Larsen, T. Explaining choice option attractiveness by beliefs elicited by the laddering method. J. Econ. Psychol. 2005, 26, 223-241.

33. Rutström, E.E.; Wilcox, N.T. Stated beliefs versus inferred beliefs: A methodological inquiry and experimental test. Games Econ. Behav. 2009, 67, 616-632.

34. Ajzen, I.; Nichols, A.J.; Driver, B.L. Identifying salient beliefs about leisure activities: Frequency of elicitation versus response latency. J. Appl. Soc. Psychol. 1995, 25, 1391-1410. 
35. Stern, P.C.; Dietz, T.; Abel, T.; Guagnano, G.A.; Kalof, L. A value-belief-norm theory of support for social movements: The case of environmentalism. Hum. Ecol. Rev. 1999, 6, 81-97.

36. Cordano, M.; Frieze, I.H. Pollution reduction preferences of U.S. Environmental managers: Applying ajzen's theory of planned behavior. Acad. Manag. J. 2000, 43, 627-641.

37. Martín-Peña, M.L.; Díaz-Garrido, E.; Sánchez-López, J.M. Relation between management's behavioral intentions toward the environment and environmental actions. J. Environ. Plan. Manag. 2010, 53, 297-315.

38. Bagozzi, R.P.; Davis, F.D.; Warshaw, P.R. Development and test of a theory of Technological Learning and Usage. Hum. Relat. 1992, 45, 659-686.

39. Venkatesh, V.; Davis, F.D. A theoretical extension of the technology acceptance model: Four longitudinal field studies. Manag. Sci. 2000, 46, 186-204.

40. Fishbein, M.; Ajzen, I. Belief, Attitude, Intention and Behaviour: An Introduction to Theory and Research; Addison-Wesley: Reading, MA, USA, 1975.

41. Ajzen, I. The theory of planned behavior. Org. Behav. Hum. Decis. Process 1991, 50, 179-211.

42. Bandura, A. Social Foundations of Thought and Action: A Social Cognitive Theory; Prentice Hall: Upper Saddle River, NJ, USA, 1985.

43. Yaryan, R.B.; Festinger, L. Preparatory action and belief in the probable occurrence of future events. J. Abnorm. Soc. Psychol. 1961, 63, 603-606.

44. Bentler, P.M.; Speckart, G. Attitudes "cause" behaviors. A structural equation analysis. J. Personal. Soc. Psychol. 1981, 40, 226-238.

45. Evetts, J. The sociological analysis of professionalism. Int. Sociol. 2003, 18, 395-415.

46. Fielding, K.S.; Terry, D.J.; Masser, B.; Hogg, M.A. Integrating social identity theory and the theory of planned behaviour to explain decisions to engage in sustainable agricultural practices. Br. J. Soc. Psychol. 2008, 47, 23-24.

47. Downs, D.S.; Hausenblas, H.A. Elicitation studies and the theory of planned behavior: A systematic review of exercise beliefs. Psychol. Sport Exerc. 2005, 6, 1-31.

48. Ajzen, I. Constructing a TpB questionnaire. Icek Ajzen Home Page. Available online: http://people.umass.edu/aizen/pdf/tpb.measurement.pdf (accessed on 22 November 2011).

49. Fonteyn, M.; Bauer-Wu, S. Using qualitative evaluation in a feasibility study to improve and refine a complementary therapy intervention prior to subsequent research. Complement. Ther. Clin. Pract. 2005, 11, 247-252.

50. NVivo Qualitative Data Analysis Software, Version 9; QSR International Pty Ltd.: Doncaster, Australia, 2010.

51. Vinnicombe, S.; Singh, V. Locks and keys to the boardroom. Women Manag. Rev. 2003, 18, 325-333.

52. Kumra, S. Exploring career choices of work-centered women in a professional service firm. Gender Manag. Int. J. 2010, 25, 227-243.

53. Kollmuss, A.; Agyeman, J. Mind the Gap: Why do people act environmentally and what are the barriers to pro-environmental behaviour? Environ. Edu. Res. 2002, 8, 239-260. 
Appendix: Interview guideline

1. Behavioral beliefs:

- What is your opinion on the LEED and the LEED AP schemes?

- Why did you include the LEED and/or the LEED AP schemes in your professional practices?

2. Normative beliefs:

- Did anyone or any organization play a major role for you to adopt LEED? Who or which organization?

- Why did you include the LEED and/or the LEED AP schemes in your professional practices?

3. Control beliefs:

- How easy is it to integrate the LEED and/or LEED AP scheme in your professional practices?

- Which factors do or may prevent you from integrating the LEED scheme in your professional practices?

4. Additional comments by respondents (open-ended).

(C) 2011 by the authors; licensee MDPI, Basel, Switzerland. This article is an open access article distributed under the terms and conditions of the Creative Commons Attribution license (http://creativecommons.org/licenses/by/3.0/). 